\title{
Finite Element Modelling of Erosion Parameters in Boiler Components
}

\author{
Prashant Kumar Singh, Amit Ranjan Hota and S.B.Mishra \\ Department of Mechanical Engineering, Motilal Nehru National Institute of Technology Allahabad, Allahabad, India \\ E-Mail: sbmishra@mnnit.ac.in
}

\begin{abstract}
Erosion wear of boiler components in power plant industry is a critical factor in predicting the life and durability of such components. In the aggressive environment, failure of components is accelerated by erosion wear. Various erosion resistant coatings have been developed in the recent past to improve the life of such components subjected to erosive wear. Among the various types of coatings, the development of WCCo ceramic coatings for the protection against erosion wear require understanding of their complex failure mechanisms occurring during solid particle impact. Many experimental works have been done to find the effect of different parameters on the erosion wear of the WC-Co coatings however such data is insufficient as newer composition and processing methods are being developed every day. Further, experimentation requires a lot of human effort, machine hours, sophisticated equipments and is time consuming. The simulation of the erosion process parameters in available finite element modelling software enables the prediction of erosion behaviour of different combination of materials. The factors affecting the erosion wear of WC-Co coating such as the particle size, the velocity of impacting particles, the coating thickness, angle of impact and the coating composition are considers in this work. The results for erosion wear are obtained and analysed using the Hashish model for erosion wear.

Keywords:WC-Co Coating, Erosion wear, Finite Element Modelling, Boiler Component
\end{abstract}

\section{INTRODUCTION}

Life of boiler components play a major role in power generation industries. The modern power plant boilers are designed to meet a number of important technical and business drivers, and an appreciation of these drivers is important to understanding the rationale behind materials selection. Generally solid solution strengthened carbide or cobalt based super-alloys are used for the boiler section of the components and carbon steels or martensitic steels are used for the boiler and heat exchanger parts [1]. Solid particles are entrained in the flow path during the air intake at compressor section and in the combustion chamber. These solid particles erode the components of the boiler section. The erosion damage of the parts not only reduces the efficiency of the boiler component but also its productivity [2]. Erosion is a complex phenomenon in mechanical industries which not only reduces the life of the components but also its productivity and efficiency. In a coal fired power plant it is often seen in many parts such as the compressor, boiler, turbine blades and flow path [3]. So it is of utmost importance to reduce the affect of erosion wear from the working components. Many erosion resistant coatings have been developed in recent past. But erosion is still dominant in the gas turbine components which work under high temperature condition. The erosion process is affected by many parameters such as the impacting particle size, shape, coating thickness, coating properties, velocity of erodent, angle of impact etc [4]. Experimental methods are reported in literature which tried to reduce the erosion wear rate by optimising the different parameters affecting it. In general, it is time consuming and labour intensive to study the erosion process experimentally and they can lead to incorrect results. And the effect of different parameters is not easy to study simultaneously by experiment [5]. Since the 1980s, computational methods, such as a finite element (FE) method, have been used to study material erosion behaviour. Initially, two dimensional (2D) models were used to investigate system parameters that affect material erosion. However, since 2D models cannot correctly consider the effects of multiple impacts and impact area overlapping, therefore three dimensional (3D) FE models have been used subsequently for erosion modelling [6].In the present investigation, a finite elememt modelling was used the study the influence the process parameter such as coating composition, erodent velocity, coating thickness, erodent particle size and impact angle on erosion behaviour of WC-Co coating. Multiple solid particles impacted as WC-Co cermet coating with boiler steelis used to simulate erosion wear using Abaqus software version 6.14.

A. Substrate and coating materials

The boiler grade steel (SAE213-T12) is selected as a substrate material considering the working condition of boiler division in coal fired power plant. The nominal chemical composition and mechanical properties of the boiler steel is shown in the Table I. The selected coating material consists of tungsten carbide (WC) with variation of Cofrom 5 to $20 \%$ as reported in Table 2. The properties of WC-Co and the variation of properties with the coating composition for simulation purpose is shown in the Table II. For the simulation purposes, the dimension of substrate was taken as $1200 \mu \mathrm{m} \times 1200 \mu \mathrm{m} \times 500 \mu \mathrm{m}$, and the coating was $1200 \mu \mathrm{m} \times 1200 \mu \mathrm{m}$ while the thickness of coating is varied in the range of $50 \mu \mathrm{m}$ to $90 \mu \mathrm{m}$. Both the coating and substrate is modelled as elasto-plastic material using abaqus/cae standard explicit package.

\section{B.Erodent particle properties}

The erodent particle used in the simulation is alumina sand having Young's modulus $300 \mathrm{GPa}$, poission's ratio 0.27 , and density $3.21 \mathrm{~g} / \mathrm{cc}$. 
TABLE INOMINAL CHEMICAL COMPOSITION AND MECHANICAL PROPERTIES OF BOILER GRADE STEEL (SAE312-T12)

\begin{tabular}{|l|c|}
\hline \multicolumn{1}{|c|}{ Substrate Material } & $\mathrm{SAE} 213-\mathrm{T} 12$ steel \\
\hline Nominal Chemical Composition & $\begin{array}{r}\mathrm{C}=0.05-0.15 \%, \\
\mathrm{Si}=0.05-1 \%, \\
\mathrm{Mn}=0.3-0.6 \%, \\
\mathrm{Cr}=1-1.5 \%, \\
\mathrm{Mo}=0.04-0.65 \%\end{array}$ \\
\hline Young's Modulus & $210 \mathrm{GPA}$ \\
\hline Poission's Ratio & 0.27 \\
\hline Yield Stress & $220 \mathrm{MPA}$ \\
\hline Density & $8.25 \mathrm{~g} / \mathrm{c}$ \\
\hline
\end{tabular}

TABLE IICOATING MATERIAL PROPERTIES

\begin{tabular}{|c|c|c|c|c|}
\hline 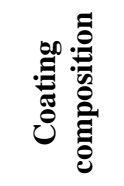 & 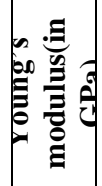 & 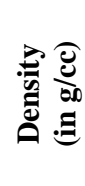 & 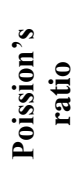 & 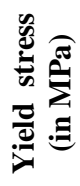 \\
\hline WC20Co & 522 & 14.26 & 0.31 & 320 \\
\hline WC15Co & 540 & 14.60 & 0.31 & 326 \\
\hline WC12Co & 554 & 14.80 & 0.31 & 330 \\
\hline WC10Co & 561 & 14.93 & 0.31 & 332 \\
\hline WC5Co & 581 & 15.26 & 0.31 & 338 \\
\hline
\end{tabular}

\section{C.Finite element modelling}

The substrate and the coating layer are perfectly brought in contact using the surface to surface contact algorithm of the interaction property manager tool. The centre of the surface of the specimen is taken as the origin. The distance between the first particle and that of the surface is kept $0.15 \mathrm{~mm}$ and that in between the particles is $0.15 \mathrm{~mm}$. Depending upon the angle of impact the particles are placed in their position. The assembly is shown in Fig. 1.

\section{Contact algorithm}

The Coulomb friction relationship as detailed in equation (1) was used in the contact model:

$$
F_{f}=\mu F_{n} \text {. }
$$

Where, $F_{f}$ the friction force, $F_{n}$ is the normal force and $\mu$ is the friction coefficient.

There is a significant difference between the stress generated on the surface during frictionless impact and that of impact with friction. However, the variation of the residual stresses and plastic strains is negligible for $0.1<\mu<0.5$ [7]. Therefore in this work, the Coulomb friction coefficient between the particle and work-piece material is assumed to be 0.2. A general explicit surface to surface contact is made between the substrate material and the coating material. During hard contact analysis, no penetration of the coating nodes are allowed into the substrate surface and no transfer of tensile stress across the interface is permitted.
Modelling of the erosion process was performed using a general purpose, commercially available, finite element solver; ABAQUS/EXPLICIT (version 6.14). It employed a Lagrangian formulation using the momentum equation

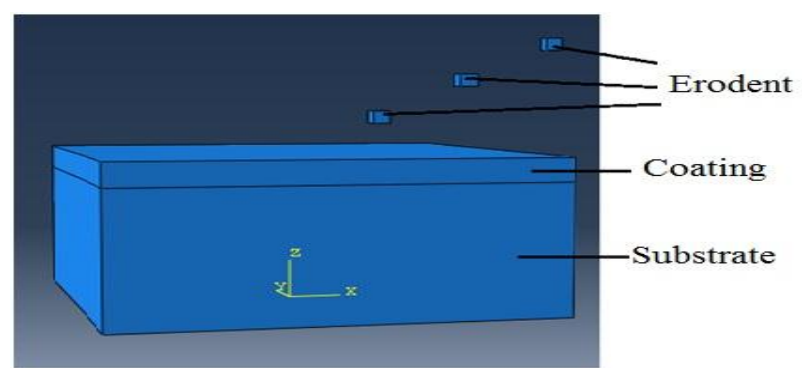

Fig. 1 Assembly of the coated specimen and particles $M \ddot{U}=F^{e x t}-F^{i n t}$

Where, $\mathrm{M}$ is the lumped mass matrix, $\ddot{U}$ is the nodal acceleration at each time step, $F^{\text {ext }}$ is the externally applied load for each node and $\mathrm{F}^{\text {int }}$ is the internal force. This set of equations is solved using explicit time integration [8]. The step time used in the work is varied depending upon the velocity used for the impacting particle and the distance between the last particle and the top of the coting surface in order to better observe the rebounding of the impacting particle and to see the effect of stress flowing over the coating surface.

In order to achieve accurate results without extensive computations the material surface is partitioned with finer mesh in the vicinity of the impact point. Eight-noded linear brick elements with reduced integration and hour glass control (C3D8R) were used to mesh the target work-piece, and the impacting particles with mesh biased toward the impact region. Fig. 2shows the meshes used for material surface and erodent particles. The approximate element size used is $0.03 \mathrm{~mm}$.

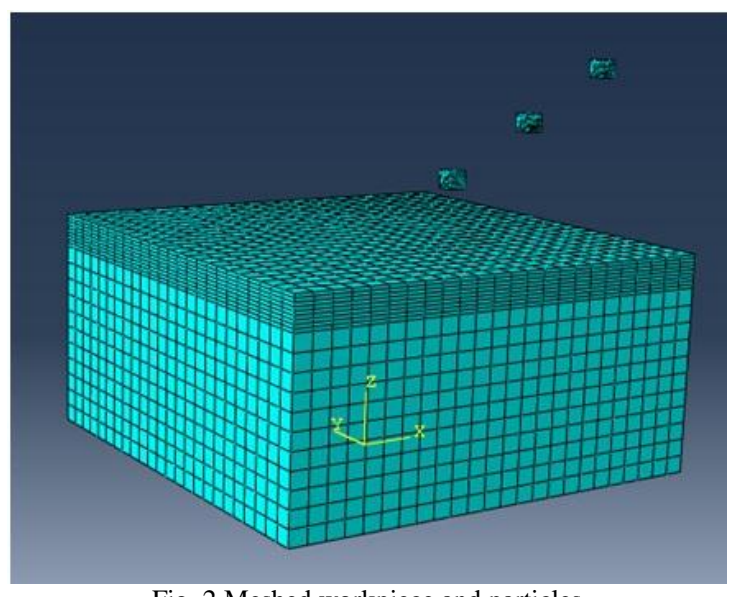

Fig. 2 Meshed workpiece and particles

For the simulation purpose following boundary conditions are used;

1. The bottom surface of the substrate is fixed i.e. no deformation is allowed in any direction. 
2. The particles are allowed only to move in 2 directions linearly while all the rotational degrees of freedoms are constrained.

3. The initial velocities of the particles are varied in the range of $50 \mathrm{~m} / \mathrm{s}$ to $100 \mathrm{~m} / \mathrm{s}$.

4. The step time for a velocity is fixed.

5. The velocities of the particles remain constant throughout the erosion process.

6. Erosion studies were carried out by varying the following parameters:

7. Coating thickness from 50 to $90 \mu \mathrm{m}$

8. Coating composition varying Co percentage from 5 to $20 \%$

9. Velocity of the erodent particle from 75 to $150 \mathrm{~m} / \mathrm{s}$

10. Angle of impact $30^{\circ}, 45^{\circ}$ and $60^{\circ}$

11. Erodent particle size 42 and $50 \mu \mathrm{m}$

\section{RESULT AND DISCUSSION}

The simulation studies for various coating compositions, coating thickness, different impacting velocities, impact angle and erodent particle sizes are carried out as reported.

\section{A. Effect of coating composition}

The simulation studies are carried out by varying the percentage of Co between 5 to $20 \%$ with rest being $\mathrm{WC}$ in the WC-Co coating. The above simulation is done by fixing the angle of impact at $45^{\circ}$, velocity of the impacting particles at $50 \mathrm{~m} / \mathrm{s}$, size of the erodent as $50 \mu \mathrm{m}$ and coating thickness 50 $\mu \mathrm{m}$ using ABACUS/CAE EXPLICIT. Three particles are impacted on the surface of coating and the results obtained for different coating compositions in the form of the surface flow stress are shown in fig. 3. Further, using Hashish model for erosion wear (equation 3 ) the wear volume of the material is calculated.

$W=\frac{7}{\pi} \frac{M}{\rho_{p}}\left(\frac{V}{C_{k}}\right)^{2.5} \sin (2 \alpha) \sin (\alpha)$

Where, $\mathrm{C}_{\mathrm{k}}$ can be computed by

$C_{k}=\sqrt{\frac{3 \sigma_{f} R_{f}^{\frac{3}{5}}}{\rho_{p}}}$

Where, $\mathrm{Rf}$ is the particle roundness factor.

Fig. 4 shows the graph between coating composition and the volume of erosion wear. From the graph it can be clearly seen that as the percentage of cobalt content decreases and WC increases the volume of the erosion wear decreases. This may be due to the fact that due to the increase in the percentage of WC phase, the hardness of the coating increases and hence more energy is required for the erodent particle to penetrate the coating surface so the wear rate decreases. Cobalt works as a binder for WC phase, but the increase in percentage of cobalt lowers the surface hardness [9]. The fact that due to the increase in hardness of coating the wear volume decreases is reported in several literature [10].

\section{B. Effect of velocity of erodent}

Particles impacting at different velocities are simulated by keeping the constant values of coating thickness, composition, angle of impact and the particle size $(50 \mu \mathrm{m}$, WC12Co, $\left.45^{\circ}, 50 \mu \mathrm{m}\right)$ throughout the simulation process. The result obtained about the surface stress is utilised to calculate the wear volume by using equation 5 . The obtained surface stresses after simulation is shown in the Fig. 5. The effect of variation of velocity on the erosion wear volume loss is depicted in Fig. 6. From the Fig. 6 it can be seen that as the velocity of the impacting particle increases the kinetic energy with which it hits the surface of the coating also increases resulting in greater penetration and hence the erosion wear volume also increases. The graph of velocity against erosion wear volume is found to follow a power law relation given by equation;

$\mathrm{Y}=2.3201 X^{1.8412}$

with $\mathrm{R}^{2}$ value of 0.9838 .

The fact that the surface stress increases as the velocity of the erodent increases is reported in literature [11-13]. As it can be seen from the graph, the increase in wear volume with the velocity can be explained by the increase of the energy content of the particles. This leads to more erosion of the work piece material at the same mass of impacting particles. In this work an exponent of 1.8412 is obtained.

\section{C.Effect of coating thickness}

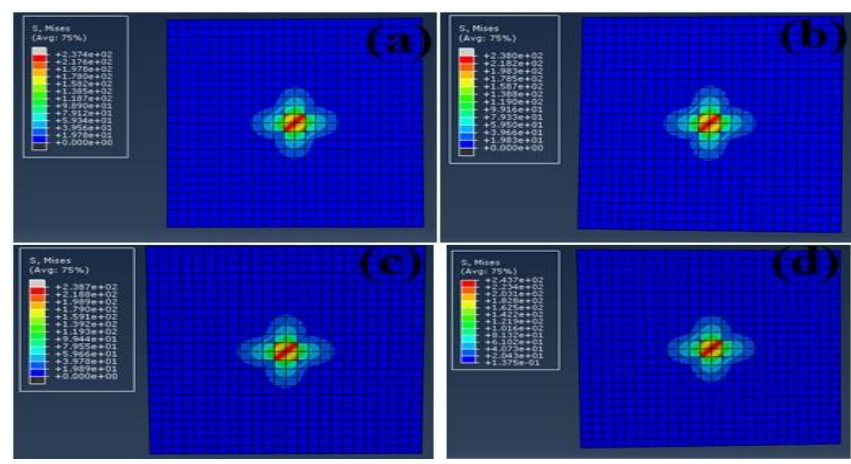

Fig. 3 Surface stresses for different coatings on SAE312-T12 steel; (a) WC15Co coating, (b) WC12Co coating, (c) WC10Co coating, (d) WC5Co coating

By varying the coating thickness from $50 \mu \mathrm{m}$ to $90 \mu \mathrm{m}$, keeping all other parameters such as velocity of the erodent, coating composition, angle of impact and particle size constant i.e. $150 \mathrm{~m} / \mathrm{s}$, WC $12 \mathrm{Co}, 45^{\circ}, 50 \mu \mathrm{m}$ respectively it is seen that the value of the surface stress goes on decreasing while this decrement is less for thicker coatings than thinner coatings. The same effect is reported by Hassani et al. [5]. The results of simulation about the surface stress is utilised to calculate the volume of erosion wear.

The obtained surface stress is shown in Fig. 7. The effect of variation of coating thickness on the erosion wear volume is depicted in Fig. 8. 
From the graph it is found that as the coating thickness increases the volume of erosion wear increases. Because for the thinner coatings the bonding between the coating and the substrate is more hence the erosion will be less and vice versa. Bielawski et al. [14] also had found out that upto certain thickness the erosion wear volume increases.

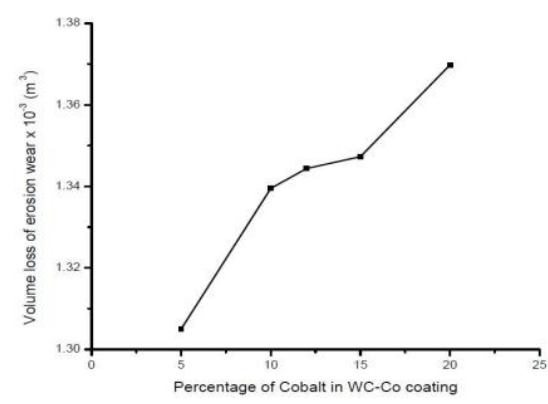

Fig. 4Effect of coating composition on volume of erosion wear

\section{Effect of Particle size and numbers}

A simulation is done by changing the particle size keeping the mass constant. In the previous results three particles are used for the simulation each having a size $50 \mu \mathrm{m}$ and here 5 particles are used having the same mass as that of the three particles hence the size of each particles is reduced to $42 \mu \mathrm{m}$.

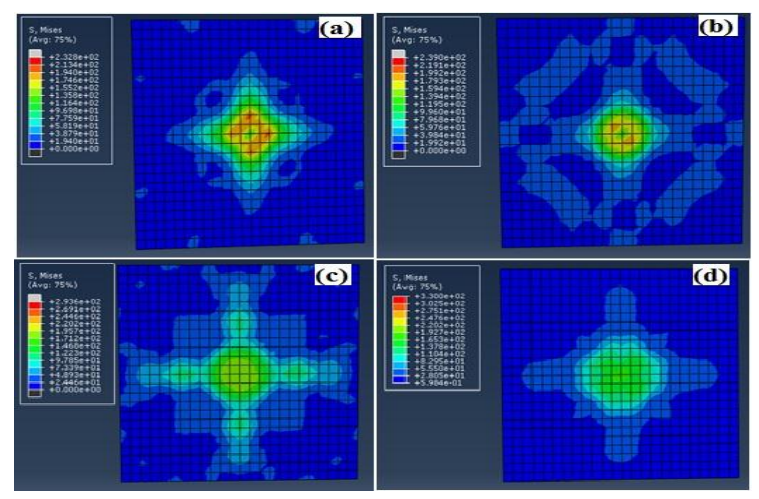

Fig. 5 Surface stresses for different velocities of impacting particles; (a) $75 \mathrm{~m} / \mathrm{s}$ (b) $100 \mathrm{~m} / \mathrm{s}$ (c) $125 \mathrm{~m} / \mathrm{s}(\mathrm{d}) 150 \mathrm{~m} / \mathrm{s}$

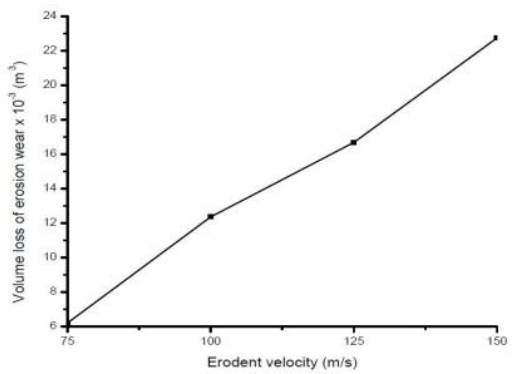

Fig. 6 Variation of velocity with erosion wear volume

All other parameters are kept constant. The velocity used is $150 \mathrm{~m} / \mathrm{s}$, coating thickness is $50 \mu \mathrm{m}$, angle of impact is $45^{\circ}$ and the coating composition used was WC12Co. The result of simulation is as shown in the Fig. 9.It is seen that the surface stress generated for the 5 particles impact which is $246.3 \mathrm{MPa}$ is less than that by 3 particles which is $330 \mathrm{MPa}$.
Again the erosion result obtained from Hashish model shows that by impacting 5 particles volume of erosion will be more which is $32790 \mu \mathrm{m}^{3}$ and that by 3 particles impact is $22740 \mu \mathrm{m}^{3}$ [15-16].

\section{E. Effect of impact angle}

The effect of impact angle as reported in literature [17] says that for ductile material the maximum erosion wear occurs at an angle ranging between $30-45^{\circ}$, and that for the brittle material it increases from 0 to $90^{\circ}$. The increasing trend of the erosion can be explained by the increasing normal component of the velocity. With higher impacting angles, higher normal component of the velocity exists, causing more erosion. Here the coating material mainly consists of tungsten carbide (WC) which is brittle in nature. So as the angle increases the erosion wear value should be increased.

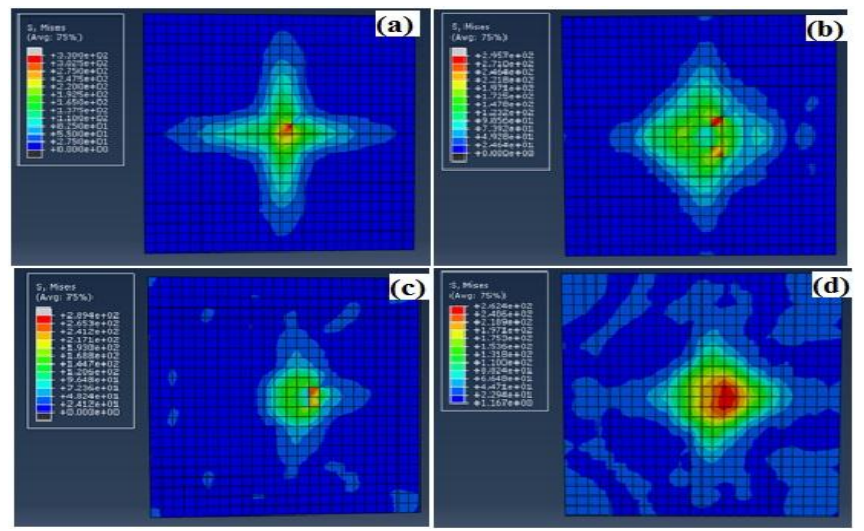

Fig. 7Surface stresses for different coating thicknesses; (a) $50 \mu \mathrm{m}$ (b) 70 $\mu \mathrm{m}(\mathrm{c}) 80 \mu \mathrm{m}(\mathrm{d}) 90 \mu \mathrm{m}$

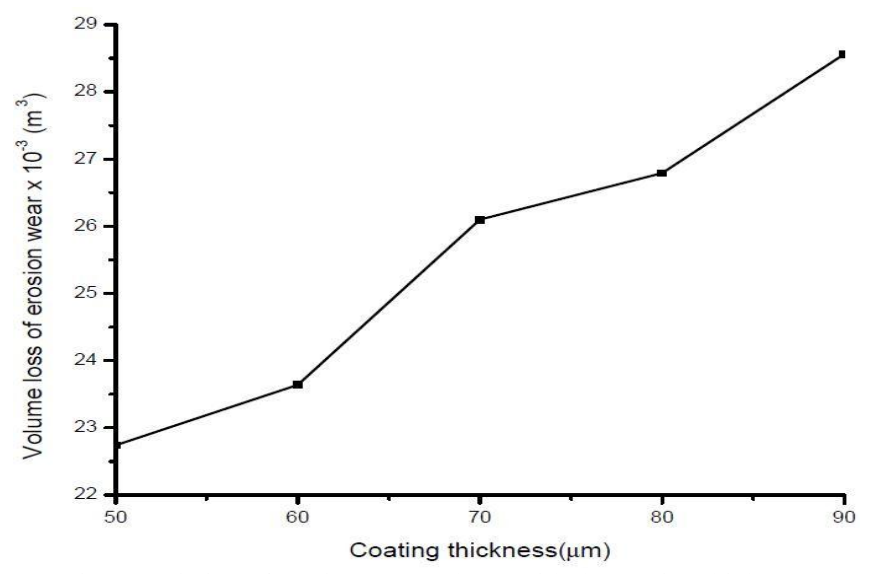

Fig. 8 Variation of erosion wear volume with the coating thickness

The simulation study is carried out by fixing the coating thickness at $50 \mu \mathrm{m}$, impacting velocity at $150 \mathrm{~m} / \mathrm{s}$, coating composition as $\mathrm{WC} 12 \mathrm{Co}$, and the particle size at $50 \mu \mathrm{m}$. The result obtained about the surface stress is utilised to calculate the wear volume by using equation 1 . The effect of variation of angle of impact on the erosion wear volume loss is depicted in Fig. 10.From the below graph it is clearly seen that in our case the erosion wear is increasing with increasing the value of impact angle, which is as reported in [18-20]. 


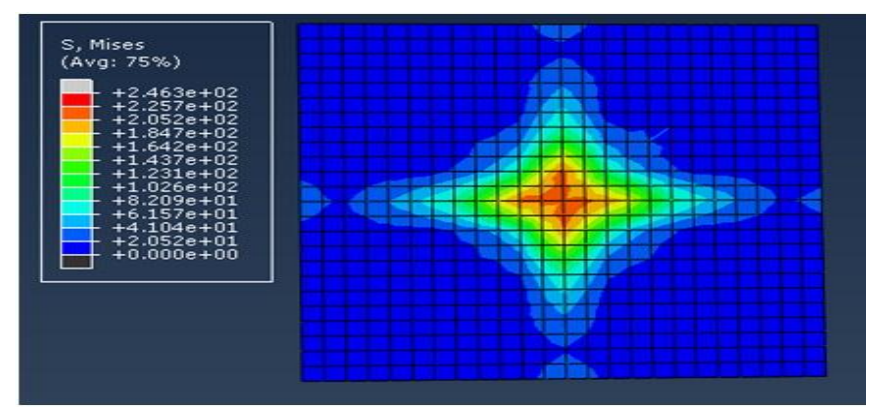

Fig. 9 Surface stress after 5 particles impact

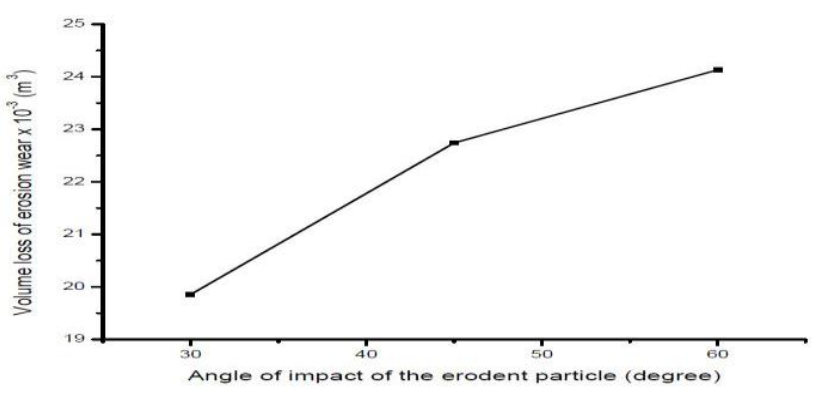

Fig. 10 Variation of erosion wear volume with angle of impact

\section{CONCLUSION}

A finite element method is used to simulate the $3 \mathrm{D}$ erosion process in this paper. The model employed was elastoplastic with material failure model. The substrate material used for the simulation is SAE312-T12 steel with a coating layer of WC-Co. The coating material has varying composition of Co with WC content and the eroding particle used for the impacting purpose is alumina sand. The effect of different parameters such as the particle velocity, angle of impact, the coating composition, coating thickness and the particle size are analysed using simulation method and Hashish model of erosion wear. The surface stress values are noted after the simulation and the values of erosion wear are calculated using the Hashish model. Following conclusions are made from the present investigation. It is observed that the as the angle of impact increases the volume of erosion wear increases suggesting the brittle nature of the coating. As the coating thickness is increased from $50 \mu \mathrm{m}$ to $90 \mu \mathrm{m}$ the wear rate is also found to be increasing. The increase in erosion wear rate with the increase in velocity follows an exponential relation with exponent 1.8412. This could possibly be due to the increase in the kinetic energy of the particles with the increase in velocity. The coating composition is varied by increasing the percentage of tungsten carbide from $80 \%$ to $95 \%$ and the rest being cobalt. It is observed that the erosion wear volume decreases with the increase in percentage of tungsten carbide in coating. As the percentage of tungsten carbide increases the hardness of the coating surface also increases and hence the impacting particle does not penetrate deeper.As the size of the impacting particles is reduced from $50 \mu \mathrm{m}$ to $42 \mu \mathrm{m}$ keeping the total mass of impacting particles constant the wear volume is also found to be increasing.

\section{REFERENCES}

[1] E. Akca and A.Gürsel, "A review on superalloys and IN718 nickelbased INCONEL superalloy,"Periodicals of Engineering and Natural Sciences.Vol. 26, No. 3, pp. 1, 2015.

[2] Q.Yang, L. Zhao and P.Patnaik, "Solid particle erosion resistant hard coatings for gas turbine engine applications,"Progress in Aircraft Icing and Aircraft erosion research-Chapter, Vol. 5,pp. 83-134, 2017

[3] R.Wei and D.W.Gandy, "Nanotechnology coatings for erosion protection of turbine components,"Journal of Engineering for Gas Turbines and Power. Vol. 132, No. 8, pp. 082104, 2010.

[4] A.P.Anaraki, J.Kadkhodapour and N.K.Farahani, "Study of solid particle impact effects and coating thickness on the erosion damage. Proceedings of the Institution of Mechanical Engineers,"Part C: Journal of Mechanical Engineering Science.Vol. 228, No. 16,pp. 2861-2870, 2014.

[5] S.Hassani, M.Bielawski, W.Beres, L.Martinu, M.Balazinski and JE.Klemberg-Sapieha, "Predictive tools for the design of erosion resistant coatings,"Surface and Coatings Technology, Vol. 25, No. 203(3-4), pp. 204-210, 2008.

[6] K.Shimizu, T.Noguchi, H.Seitoh, M.Okada and Y.Matsubara, "FEM analysis of erosive wear," Wear,Vol. 250, No. 1-12,pp. 779-784, 2001.

[7] G.E. Dieter and D.J.Bacon, Mechanical metallurgy. New York: McGraw-hill; 1986.

[8] M.S.ElTobgy, E. Ng and M.A.Elbestawi, "Finite element modeling of erosive wear,"International Journal of Machine Tools and Manufacture, Vol. 45, No. 11,pp. 1337-1346,2005.

[9] M.S.Mahdipoor,F.Tarasi, C.Moreau, A.Dolatabadi and M. Medraj, "HVOF sprayed coatings of nano-agglomerated tungstencarbide/cobalt powders for water droplet erosion application", Wear, Vol. 330,pp. 338-347, 2015.

[10] Y.Li, Y.Lian, J.Cao and L.Li, "Solid particle erosion behavior of HVOF/HVAF sprayed WC-Co-Cr coatings", Proceedings of the Institution of Mechanical Engineers, Part J: Journal of Engineering Tribology, Vol. 230, No. 6,pp. 634-643, 2016.

[11] B.A. Lindsley and A.R.Marder, "The effect of velocity on the solid particle erosion rate of alloys," Wear,Vol. 225,pp. 510-516, 1999.

[12] S.G. Sapate and A.V.RamaRao, "Effect of erodent particle hardness on velocity exponent in erosion of steels and cast irons," Materials and Manufacturing Processes, Vol. 18, No. 5, pp. 783-802, 2003.

[13] R.O. Scattergood and J.L.Routbort, "Velocity Exponent in Solid- Particle Erosion of Silicon," Journal of the American Ceramic Society, Vol. 66, No. 10, pp.184-186, 1983.

[14] M.Bielawski and W.Beres, "Effect of coating architecture on impact stress distribution in particulate erosion condition," InJournal of Physics: Conference Series, Vol. 100, No. 8, 2008.

[15] D.B.Marshall, A.G.Evans, M.E.Gulden,J.L.Routbort and R.O.Scattergood, "Particle size distribution effects on the solid particle erosion of brittle materials," Wear, Vol. 71, No. 3,pp. 363-73, 1981.

[16] V.B.Nguyen, Q.B.Nguyen, Y.W.Zhang, C.Y. Lim, and BC.Khoo, "Effect of particle size on erosion characteristics," Wear, 348: p. 12637, 2016

[17] S.K.Das, K.M.Godiwalla, S.P.Mehrotra, K.K.Sastry and P.K.Dey, "Analytical model for erosion behaviour of impacted fly-ash particles on coal-fired boiler components," Sadhana, Vol. 31, No. 5, pp. 583595, 2006.

[18] D.Griffin, A.Daadbin and S.Datta, "The development of a threedimensional finite element model for solid particle erosion on an alumina scale/MA956 substrate", Wear, Vol. 256, No. 9-10,pp. 900906, 2004.

[19] Y.I.Oka, H.Ohnogi, T.Hosokawa and M.Matsumura, "The impact angle dependence of erosion damage caused by solid particle impact," Wear, Vol. 203,pp. 573-579, 1997.

[20] Y.Yıldıran,E.Avcu,A.E.Şahin,S. Fidan, H. Yetiştiren and T.Sınmazçelik, "Effect of particle impact angle, erodent particle size and acceleration pressure on the solid particle erosion behavior of 3003 aluminum alloy," Acta Physica Polonica A, Vol. 125, No. 2, pp. 523-525, 2014. 